\title{
Thunderclap headache without hypertension in a patient with pheochromocytoma
}

\author{
Masahiko Watanabe $\cdot$ Akimitsu Takahashi · \\ Hitoshi Shimano $\cdot$ Hisato Hara $\cdot$ Shintaro Sugita $\cdot$ \\ Kiyotaka Nakamagoe $\cdot$ Akira Tamaoka
}

Received: 12 April 2010/Accepted: 6 June 2010/Published online: 13 July 2010

(C) Springer-Verlag 2010

\begin{abstract}
Pheochromocytoma is a well known, catecholamine-producing tumor characterized by hypertension, headache, hyperglycemia, hypermetabolism, and hyperhydrosis. Approximately $65 \%$ of cases of pheochromocytoma were shown to be associated with hypertension. A case of pheochromocytoma that presented with thunderclap headache (TCH) and palpitations is reported. The patient never showed hypertension during the course of the disease. Paroxysmal headache and palpitations led to the identification of the underlying condition, and the final diagnosis was confirmed by histopathological examination of a surgical specimen. Pheochromocytoma should be identified as a less common although important cause of TCH. In addition, due to its lack of utility in identifying this disorder, negative cranial imaging may impede further investigation of extracranial lesions that may be the cause of a patient's headache. According to
\end{abstract}

M. Watanabe $(\square) \cdot$ K. Nakamagoe $\cdot$ A. Tamaoka Department of Neurology, University of Tsukuba, 1-1-1 Tennodai, Tsukuba, Ibaraki, Japan

e-mail: masa-wat@md.tsukuba.ac.jp

A. Takahashi $\cdot$ H. Shimano

Department of Endocrinology and Metabolism,

University of Tsukuba, Tsukuba, Ibaraki, Japan

H. Hara

Department of Breast-Thyroid-Endocrine Surgery,

University of Tsukuba, Tsukuba, Ibaraki, Japan

\section{S. Sugita}

Department of Pathology, University of Tsukuba,

Tsukuba, Ibaraki, Japan the International Classification of Headache Disorders (ICHD)-II, headache attributed to pheochromocytoma usually develops concomitantly with an abrupt increase in blood pressure. In our case, however, hypertension was never observed, even when the patient was symptomatic. This is the first report of a case of pheochromocytoma with TCH without hypertension.

Keywords Pheochromocytoma - Thunderclap headache . Hypertension · Palpitation

\section{Introduction}

Thunderclap headaches (TCHs) is characterized by a sudden onset of severe head pain that peaks within 1 min of onset. Although benign primary TCHs are described in the International Classification of Headache Disorders-II, TCHs are considered to be symptomatic of subarachnoid hemorrhages, and their importance in diagnosis of acute illness by exclusion is specially mentioned. In a case with a chief complaint of sudden headaches, we succeeded in detecting the presence of a pheochromocytoma because of the accompanying palpitations. There is a danger of laxness in the differential diagnosis of TCH cases once the possibility of subarachnoid hemorrhage is excluded. We present a case that may affect the long-term prognosis of $\mathrm{TCH}$ patients in which the decisive factor in the differential diagnosis of TCH was detected by abdominal imaging rather than head imaging.

\section{Case}

A patient was a 33-year-old Japanese woman. 


\section{Chief complaint}

Sudden intense headaches and palpitations.

Past medical history

The patient had experienced migraines without aura, since her early 20s. She had right ovarian cysts resected at 26 years of age and a myomectomy at 32 years of age.

\section{Family history}

No family history of headaches, thyroid tumor, or hyperparathyroidism was present.

\section{Current medical history}

On the 10th of 10 years, while resting after lunch, the patient experienced sudden intense palpitations immediately followed by a severe pulsating headache. Although there was no nausea or vomiting, the patient described it as the "worst headache of my entire life." After continuing for about $1 \mathrm{~h}$, the headache gradually disappeared with rest. Because a similar attack occurred on the following day, the patient was seen at the neurosurgery department at her local hospital 2 days after initial occurrence. A cranial CT scan was performed on the same day. Owing to the relatively short duration of her headache, negative neurological examination, and negative brain CT scan, the patient was judged to have no abnormalities or need a lumbar puncture. The neurosurgeon prescribed loxoprofen, etizolam, but there was not much effect.

After 10 days of examination, the patient underwent an outpatient migraine examination because of similar, frequent and intense headaches.

\section{Current illness}

The patient had a normal blood pressure and heart rate on physical examination. There were no special neurological findings.

\section{Laboratory findings}

There were no abnormalities on standard blood and urine tests; thyroid functions were also normal. iPTH levels were $43 \mathrm{pg} / \mathrm{ml}$, blood noradrenaline levels were $1,340 \mathrm{pg} / \mathrm{ml}$, adrenaline levels were $61 \mathrm{pg} / \mathrm{ml}$, and dopamine levels were $21 \mathrm{pg} / \mathrm{ml}$. Because noradrenaline levels were significantly elevated, abdominal ultrasonography was performed. A well defined, roughly spherical tumor, with a diameter of $3.6 \mathrm{~cm}$ and partial cystic degeneration, located within the left adrenal gland was found. With these findings, the patient was strongly suspected of having pheochromocytoma, and was hospitalized for detailed examinations in the metabolic internal medicine department. Urinary normetanephrine and metanephrine levels were significantly elevated $(2,593 \mu \mathrm{g} / \mathrm{ml})$. On MIBG scintigraphy, an area of high uptake corresponding to the left adrenal gland was detected (Fig. 1). Cranial MRI was done on seventh day of her admission, 2 days after the most recent headache attack.

\section{Clinical progression}

The patient's blood pressure was within the normal range for the duration of this study, including during both headache occurrence and non-occurrence. There were seven headache during hospitalization of 18 days. The average blood pressure for this time period was $112.6 / 66.0 \mathrm{mmHg}$; no evidence of hypertension was observed. The average

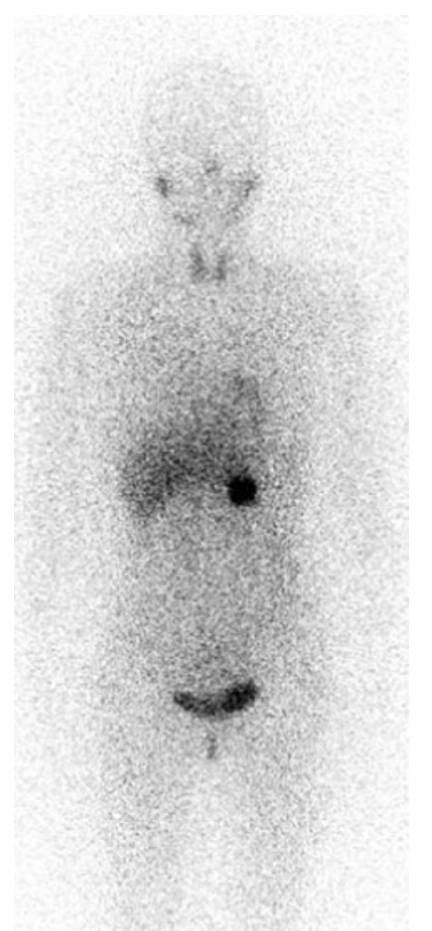

Fig. 1 An area of high uptake conforming to the left adrenal gland is seen 
Table 1 Previously reported cases of TCH with pheochromocytoma

\begin{tabular}{lllll}
\hline References & $\begin{array}{l}\text { Age } \\
\text { (years) }\end{array}$ & Sex & Headache & Associated symptoms \\
\hline Sanyal and Fletcher [6] & 45 & Male & Sudden, short, excruciating & $\begin{array}{c}\text { Pulsating sensation } \\
\text { in abdomen and chest }\end{array}$ \\
Heo et al. [4] & 45 & Female & Explosive, pulsatile, worst of her life & $\begin{array}{c}\text { None } \\
\text { Sweating, conjunctival } \\
\text { injection, restlessness }\end{array}$ \\
Im and Kim [3] & 37 & Male & Sudden, pulsating, worst of his life & $\begin{array}{c}\text { Palpitations } \\
\text { This case }\end{array}$ \\
\hline
\end{tabular}

heart rate during headache occurrence was $88.0 \mathrm{bpm}$; however, the patient reported experiencing palpitations three times. We administered prazosin hydrochloride and nifedipine to restore her circulating blood volume. A laparoscopic adrenalectomy was performed 2 months later, and a macroscopically well defined, solid tumor measuring $3 \times 3 \times 2.7 \mathrm{~cm}$ was found in the left adrenal gland.

\section{Histopathology}

The tumor consisted of solid and fascicular proliferation of polygonal and rhombic cells. The tumor cells had hyperchromatic round nuclei with a rough chromatin pattern and basophilic cytoplasm. On immunohistochemical analyses, the tumor cells were positive for CD56, chromogranin A, and synaptophysin. From these results, the tumor was diagnosed as a pheochromocytoma.

\section{Discussion}

Thunderclap headaches occur suddenly, with pain intensity peaking in under $1 \mathrm{~min}$ and continuing from $1 \mathrm{~h}$ to 10 days. The most dangerous condition associated with headaches meeting these criteria is subarachnoid hemorrhage; however, numerous other diseases involving the vasculature of the central nervous system, such as ischemic stroke [1], cerebral venous thrombosis, cervical artery dissection, acute hypertensive crisis, retroclival hematoma, pituitary apoplexy and non-vascular structure of the central nervous system, such as spontaneous intracranial hypotension, third ventricle colloid cyst, and intracranial infection [2] are found on the list of diseases that should be excluded in the differential diagnosis. Therefore, TCH is a particularly important symptom in differential diagnosis by cranial imaging. However, it is extremely important to bear in mind that many other diseases associated with TCHs, such as pheochromocytoma [3-6] and, myocardial infarction cannot be detected with cranial imaging and may have serious outcomes.

Characteristic symptoms accompanying headaches in cases of pheochromocytoma, include perspiration, palpitations, anxiety, and facial pallor; headaches are known to occur simultaneously with sudden blood pressure elevation [7]. Other than the present patients, all reported cases of pheochromocytoma with accompanying TCHs have included high blood pressure (Table 1) [3-6]. Although many of the patient's headache occurring while under observation in the hospital were accompanied by palpitations, blood pressure was within normal range during the headaches. Observation of normal or low blood pressure in pheochromocytoma cases is not particularly rare [8], and it is known that catecholamine levels in the circulating blood are not well correlated with blood pressure. There are other cases in which hypertension was not observed, despite confirmation of urinary catecholamine metabolite elevation [9]. Possible reasons for the observation of normal blood pressure in cases with pheochromocytoma (which is a catecholamine-producing tumor) include: (1) reduced circulating plasma volume due to continuous vasoconstriction; (2) individual differences in the catecholamine metabolic rate and related reactions, and (3) the effects of strong vasodilating agents (such as calcitonin gene-related peptides and adrenomedulin) [10] produced by the tumor [9].

This case study suggests that pheochromocytoma should be included in the differential diagnosis of TCHs with accompanied by palpitations, even when the blood pressure is normal. We would also like to propose that headache occurring concurrently with sudden blood pressure elevation may be inadequate as diagnostic criteria for headaches caused by pheochromocytoma.

\section{Conflict of interest None.}

\section{References}

1. Edwardsson BA, Persson S (2009) Cerebral infarct presenting with thunderclap headache. J Headache Pain 10:207-209

2. Schwedt TJ, Matharu MS, Dodick DW (2006) Thunderclap headache. Lancet Neurol 5:621-631

3. Im SH, Kim NH (2008) Thunderclap headache after micturition in bladder pheochromocytoma. Headache 48:965-967

4. Heo YE, Kwon HM, Nam HW (2008) Thunderclap headache as an initial manifestation of phaeochromocytoma. Cephalalgia 29:388-390 
5. Udayakumar N, Sivaprakash S, Chandrasekaran M (2007) Headache as the only sign of pheochromocytoma: an analysis. Indian J Med Sci 61:611-613

6. Sanyal K, Fletcher S (2009) Headache as a sign of phaeochromocytoma. Emerg Med J 26:71

7. Headache Classification Subcommittee of the International Headache Society (2004) The International Classification of Headache Disorders; Edition. Cephalalgia 24(Suppl 1):1-160

8. Bravo EL, Tarazi RC, Gifford RW, Stewart BH (1979) Circulating and urinary catecholamine in pheochromocytoma: diagnostic and pathophysiologic implications. N Eng J Med 301:682-686

9. Agarwal A, Gupta S, Mishra AK, Singh N, Mishra SK (2005) Normotensive pheochromocytoma: institutional experience. World J Surg 29:1185-1188

10. Kitamura K, Kangawa K, Kuwamoto M, Ichiki Y, Nakamura S, Matsuo H (1993) Adrenomedulin: a novel hypotensive peptide isolated from human pheochromocytoma. Biochem Biophys Res Commun 192:553-560 